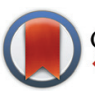

CrossMark \& click for updates

Cite this: Polym. Chem., 2015, 6 , 6351

Received 20th April 2015,

Accepted 12th July 2015

DOI: 10.1039/c5py00576k

www.rsc.org/polymers

\title{
One-pot approach to Pd-loaded porous polymers with properties tunable by the oxidation state of the phosphorus core $\uparrow$
}

\author{
Xiaoyu Jiang, $\star^{\mathrm{a}}$ Wuxue Zhao, $\ddagger^{\mathrm{b}}$ Wei Wang, ${ }^{{ }^{\mathrm{a}}}$ Fan Zhang, ${ }^{{ }^{\mathrm{b}}}$ Xiaodong Zhuang, ${ }^{\mathrm{b}}$ \\ Sheng $\operatorname{Han}^{\mathrm{c}}$ and Xinliang Feng ${ }^{\mathrm{d}}$
}

\begin{abstract}
Two novel Pd-loaded heteroatom-linked microporous polymers $\mathrm{Pd} @ \mathrm{~N}=\mathrm{P}$ and $\mathrm{Pd} \mathrm{N}=\mathrm{P}=\mathrm{O}$ were effectively synthesized by one-pot $\mathrm{Pd}$-catalyzed Heck coupling reactions of tris(4-vinylphenyl)amine with tris (4-bromophenyl)phosphine and tris(4-bromophenyl)phosphine oxide, respectively. The Pd atoms loaded into the networks of the resulting porous polymers originated from the Pd-catalyst used in the polymerization, which was achieved under moderate reaction conditions. Besides the nitrogen atoms, the trivalent phosphorus atoms bearing one lone pair of electrons and the pentavalent phosphorus atoms of the phosphoryl groups were used as the linkers for the formation of the frameworks of the porous polymers $\mathrm{Pd} a \mathrm{~N}=\mathrm{P}$ and $\mathrm{Pd} \mathrm{aN}=\mathrm{P}=\mathrm{O}$, respectively. The phosphorus atoms with different oxidation states in the networks caused a dramatic variation in the physical and catalytic properties of the as-prepared porous polymers. $\mathrm{Pd} \cap \mathrm{N}=\mathrm{P}$ and $\mathrm{Pd} @ \mathrm{~N}=\mathrm{P}=\mathrm{O}$ exhibit surface areas of $381 \mathrm{~m}^{2} \mathrm{~g}^{-1}$ and $684 \mathrm{~m}^{2} \mathrm{~g}^{-1}$, respectively. Both $\mathrm{Pd}$-loaded porous polymers enable efficient Suzuki-Miyaura coupling reactions featuring short reaction times and good yields, with the catalysts being highly stable and easy to recycle. The catalytic activity of $\mathrm{Pd} @ \mathrm{~N}=\mathrm{P}=\mathrm{O}$ is higher than that of $\mathrm{Pd} \mathrm{aN}=\mathrm{P}$.
\end{abstract}

\section{Introduction}

During the past decades, carbon-carbon and carbon-heteroatom coupling reactions have made great progress in synthetic organic chemistry. Among the varieties of coupling methods, the Suzuki-Miyaura reaction is one of the most common and efficient methods for the application of carbon-carbon bond formation and it has been extensively investigated. ${ }^{1}$ However, the practical application of these reactions on a large scale remains a big challenge, typically due to the following three reasons: ${ }^{2,3}$ (1) expensive catalysts with a requirement for a large excess of ligands; (2) sensitivity of the catalytic systems to air; (3) the difficult recovery of the product as well as the low reusability and recycling of the catalysts. As one of the avail-

\footnotetext{
${ }^{a}$ School of Perfume and Aroma Technology, Shanghai Institute of Technology, Shanghai, 200235, P. R. China. E-mail: wangweittg@sit.edu.cn

${ }^{b}$ School of Chemistry and Chemical Engineering, Shanghai Jiao Tong University, Shanghai 200240, China. E-mail: fan-zhang@sjtu.edu.cn

${ }^{c}$ School of Chemical and Environmental Engineering, Shanghai Institute of Technology, Haiquan Road 100, Shanghai, P. R. China

${ }^{d}$ Center for Advancing Electronics Dresden \& Department of Chemistry and Food Chemistry, Technische Universitaet Dresden, 01062 Dresden, Germany

$\dagger$ Electronic supplementary information (ESI) available. See DOI: 10.1039/ c5py00576k

$\$$ These two authors contributed equally to this work.
}

able strategies of addressing these issues, researchers have successfully combined Pd nanoparticles with various supports, including porous silicon dioxide, ${ }^{4}$ metal oxides, ${ }^{5}$ carbon structures, ${ }^{6}$ covalent organic frameworks (COFs) ${ }^{7}$ and microporous organic polymers (MOPs), ${ }^{8}$ to develop heterogeneous catalysts.

Microporous organic polymers (MOPs), composed of C, H, $\mathrm{O}, \mathrm{N}$ and other main group elements, are a new class of porous material with nano-scale porosity and they have attracted tremendous attention due to their porous structures associated with prominent physical properties and potential applications, such as in light harvesting, ${ }^{9}$ sensing, ${ }^{10}$ gas separation and storage, ${ }^{11,12}$ catalysis, ${ }^{8,13}$ and energy storage and conversion. ${ }^{14}$ According to different design strategies, MOPs can be separated into the following four kinds: (1) conjugated microporous polymers (CMPs); ${ }^{15,16}$ (2) hyper-cross-linked polymers (HCPs); ${ }^{17,18}$ (3) covalent microporous organic frameworks $(\mathrm{COFs}){ }^{19,20}$ (4) polymers of intrinsic microporosity (PIMs). ${ }^{21,22}$ Conjugated microporous polymers (CMPs) represent one of the fastest developing types of porous materials because of their outstanding properties of good thermal and chemical stability, high surface area and well-defined porosity. ${ }^{15}$ In particular, some CMPs which contain functional units such as bipyridines, ${ }^{23}$ metalloporphyrins, ${ }^{24,25}$ and triazine rings ${ }^{26,27}$ have been used to construct heterogeneous catalytic systems by loading Pd nanoparticles onto the networks in one or two 
steps, which is much more effective and controllable than those of traditional methods in the other porous supports. ${ }^{28-30}$ Notably, phosphorus (P), as a light element with facile chemical modification, has been widely used for tuning the photophysical and electrochemical properties of functional materials, such as, organic light-emitting diodes (OLEDs) ${ }^{31}$ and electron transport materials (ETMs), ${ }^{32}$ and also constructing various chelated ligands. ${ }^{33}$ Very recently, several P-containing porous polymers have been successfully achieved. ${ }^{34,35}$ In these reports, the phosphorus atom acts as either a linker for the formation of the cross-linked network, a functional moiety to achieve phosphorescent emitters ${ }^{36}$ or as a ligand of heterogeneous catalysts. ${ }^{37}$ The phosphorus atom, with different valence states, has been used for tuning the luminescence properties of a functional material. However, as far as we know, it has been used less for affecting the structural characteristics of a porous material by changing the valence states of the heteroatoms (e.g. P) in the network. In this paper, we have successfully developed an effective approach to synthesize two novel Pd-loaded microporous polymers by a one-pot palladium-catalyzed Heck cross-coupling reaction of tris(4-vinylphenyl)amine with either tris(4-bromophenyl)phosphine or tris(4bromophenyl)phosphine oxide under mild experimental conditions. This method of combining the palladium catalyst with the in situ catalyzed polymerization, enables the confinement of the nascent Pd particles in the polymer networks. The two kinds of porous polymers exhibit remarkably different thermal stabilities and porous structures. They exhibit high activities for catalyzing Suzuki-Miyaura coupling reactions, even in aerobic conditions, and they can be recycled and reused for at least three cycles without significant deactivation. Their porous structures also offer a steric influence for size-selectively catalyzing substances with different molecular sizes. The differences in the properties of the as-prepared polymers can mainly be attributed to the phosphorus atoms with different valance states in the networks.

\section{Experimental section}

\section{Reagents and chemicals}

Triphenylamine, 1,4-dibromobenzene, phosphorus oxychloride, methyl phosphonium iodide, $\mathrm{NaH}$, and $n$-butyllithium were purchased from Aladdin and Aldrich. All solvents were dried before use. $N, N$-Dimethylformamide (DMF) was dried with $\mathrm{CaH}_{2}$ and then distilled under reduced pressure before use. Tetrahydrofuran (THF) was refluxed with sodium. All airsensitive reactions were carried out in a nitrogen atmosphere and performed with Schlenk techniques. The key building blocks of tris(4-bromophenyl)phosphine, ${ }^{31}$ tris(4-formylphenyl)amine, ${ }^{38}$ tris(4-vinylphenyl)amine, ${ }^{38}$ and tris(4-bromophenyl)phosphine oxide ${ }^{39}$ were synthesized by modified protocols of the previous reports.

The Pd-loaded porous polymers were prepared via a typical Pd-catalyzed Heck cross-coupling polymerization.

\section{Synthesis of the porous polymer $\mathbf{P d} @ N=P$}

Tris(4-vinylphenyl)amine (126.0 mg, $0.39 \mathrm{mmol})$, tris(4-bromophenyl)phosphine (193.4 $\mathrm{mg}, 0.39 \mathrm{mmol}$ ), and $\mathrm{K}_{2} \mathrm{CO}_{3}$ (357.2 $\mathrm{mg}, 2.73 \mathrm{mmol}$ ) were used in a mixture of anhydrous DMF $(10 \mathrm{~mL})$. The reaction mixture was treated three times by freezing and thawing, and then tetrakis(triphenylphosphine) palladium(0) (16.5 mg, $0.015 \mathrm{mmol}$ ) was added. The combined mixture was treated two times by freezing and thawing again, and then it was heated up and stirred at $120^{\circ} \mathrm{C}$ for $72 \mathrm{~h}$ under a nitrogen atmosphere. After the reaction mixture was cooled to room temperature, the resulting precipitate was filtered and collected to afford the crude product which had a yellow colour. According to a typical workup for a porous polymer, the crude product was sequently washed with water, chloroform, methanol, and acetone several times and then treated by Soxhlet extraction with THF for $24 \mathrm{~h}$ and dried under vacuum at $80{ }^{\circ} \mathrm{C}$ for $4 \mathrm{~h}$ to give $\mathrm{Pd} @ \mathrm{~N}=\mathrm{P}$ as a yellow solid (145 $\mathrm{mg}, 83 \%)$.

\section{Synthesis of the porous polymer $\mathrm{Pd} @ \mathrm{~N}=\mathrm{P}=\mathrm{O}$}

Using the reactants tris(4-vinylphenyl)amine $(126.0 \mathrm{mg}$, $0.39 \mathrm{mmol}$ ), tris(4-bromophenyl)phosphine oxide (199.6 mg, $0.39 \mathrm{mmol}), \mathrm{K}_{2} \mathrm{CO}_{3}(357.2 \mathrm{mg}, 2.73 \mathrm{mmol})$ and tetrakis(triphenylphosphine)palladium(0) (16.5 mg, $0.015 \mathrm{mmol})$ in $10 \mathrm{~mL}$ of DMF, a similar procedure as mentioned above was performed to give $\mathrm{Pd} @ \mathrm{~N}=\mathrm{P}=\mathrm{O}$ as a yellow solid (156 mg, 88\%).

\section{Catalytic properties of the as-prepared porous polymers}

As an example, a typical procedure is presented: to a reaction tube boronic acid (1.2 mmol, 1.2 equiv.), potassium carbonate (276.0 mg, $2 \mathrm{mmol}$, and 2.0 equiv.), aryl bromide or aryl chloride (1.0 mmol, 1.0 equiv.), $\mathrm{Pd} @ \mathrm{~N}=\mathrm{P}(0.1 \mathrm{~mol} \% \mathrm{Pd}$ based on arylbromide), ethanol $(6 \mathrm{~mL})$ and water $(2 \mathrm{~mL})$ were added and then tube was sealed with a Teflon screw cap. All these additions were done in air, and the reaction system did not undergo any extra treatment, such as degassing. The reaction mixture was stirred in a preheated oil bath $\left(70^{\circ} \mathrm{C}\right)$. The reaction progress was monitored by TLC analysis. After cooling down to room temperature, the product was extracted into dichloromethane and washed with water to remove any potassium carbonate. Further purification was done via column chromatography over silica gel to afford the desired crosscoupling products. In recycling tests, the catalyst was simply washed with dichloromethane, water, and ethanol and then dried, it was then used again directly after each cycle.

\section{Characterization}

Fourier transform infrared (FTIR) spectra were recorded with a Spectrum 100 spectrometer (Perkin Elmer, Spectrum 100). X-ray powder diffraction patterns were recorded with a transmission geometry using a Rigaku X-ray diffractometer with $\mathrm{Cu}-\mathrm{K} \alpha$ irradiation $(\lambda=0.15406 \mathrm{~nm})$ at $40 \mathrm{kV}, 20 \mathrm{~mA}$ over the $2 \theta$ range from 5 to $60^{\circ}$. Thermogravimetric analysis (TGA) was measured by a TAQ5000IR with a heating rate of $20{ }^{\circ} \mathrm{C} \mathrm{min}^{-1}$ under flowing $\mathrm{N}_{2}$. X-ray photoelectron spectroscopy (XPS) 
experiments were carried out on an AXIS Ultra DLD system from Kratos with $\mathrm{Al} \mathrm{K} \alpha$ radiation as the X-ray source for the radiation. Solid-state ${ }^{13} \mathrm{C}$ CPMAS NMR was conducted on a Bruker AVANCE III 300 Spectrometer. Samples were spun at $5 \mathrm{kHz}$ in $4 \mathrm{~mm}$ zirconium rotor within a MAS probe. An acquisition time of $20 \mathrm{~ms}$, a contact time of $1 \mathrm{~ms}$ and a $6.5 \mu \mathrm{s}$ prescan delay were used. The recycle time was $2 \mathrm{~s}$ to obtain fully relaxed spectra. Chemical shifts were externally referenced to adamantane at $38.48 \mathrm{ppm}$. Elemental analysis was carried out using inductively coupled plasma emission spectrometer (ICP) analyses on an iCAP 6000 Radial. The fluorescence spectroscopy emission spectra were obtained with a FluoroMax-4 spectrophotometer. SEM measurements were performed on a FEI Sirion200 field emission scanning electron microscope. Transmission electron microscopy (TEM) characterizations were conducted using a JEM-2100 (JEOL Ltd, Japan) with an accelerating voltage of $200 \mathrm{KV}$. Nitrogen sorption isotherm measurements were performed on a Micromeritics ASAP 2010 surface area and pore size analyzer at $77 \mathrm{~K}$. Prior to the measurement, the samples were degassed in a vacuum at $200{ }^{\circ} \mathrm{C}$ for $12 \mathrm{~h}$.

\section{Results and discussion}

The synthetic routes are shown in Scheme 1. Tris(4-vinylphenyl)amine was polymerized with either tris(4-bromophenyl)phosphine or tris(4-bromophenyl)phosphine oxide using a typical Pd-catalyzed Heck cross-coupling reaction to form a yellow coloured precipitate, which was washed with water, chloroform, methanol, and acetone and further purified with THF to afford the porous polymers Pd@N=P (yield: $83 \%$ ) and $\mathrm{Pd} @ \mathrm{~N}=\mathrm{P}=\mathrm{O}$, (yield: $88 \%$ ), respectively. The components of the resulting porous polymer samples were analyzed by inductively coupled plasma (ICP) analysis, showing the presence of the Pd element in the networks, with a content of $1.0 \mathrm{wt} \%$ and $0.89 \mathrm{wt} \%$ for $\mathrm{Pd} @ \mathrm{~N}=\mathrm{P}$ and $\mathrm{Pd} @ \mathrm{~N}=\mathrm{P}=\mathrm{O}$, respectively. The asprepared polymer samples were almost insoluble in common organic solvents, e.g. toluene, tetrahydrofuran, dimethylformamide, dichloromethane, methanol, acetone etc.

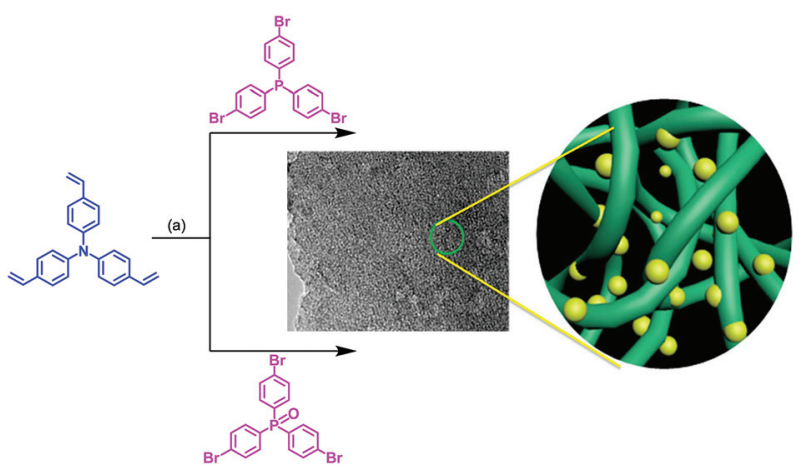

Scheme 1 Synthetic procedure for the porous polymers $\mathrm{PdaN}=\mathrm{P}$ and $\mathrm{PdON}=\mathrm{P}=\mathrm{O}$ where (a) is $\mathrm{K}_{2} \mathrm{CO}_{3}, \mathrm{Pd}\left(\mathrm{PPh}_{3}\right)_{4}, \mathrm{DMF}, 120^{\circ} \mathrm{C}$, and $72 \mathrm{~h}(\mathrm{C}$ porous framework; $\mathrm{Pd}$ particle).
The chemical structures of the polymers were confirmed by ${ }^{13} \mathrm{C}$ solid-state and ${ }^{31} \mathrm{P}$ solid-state nuclear magnetic resonance (NMR) spectroscopy. In the solid-state ${ }^{13} \mathrm{C}$ CP/MAS NMR spectra (Fig. 1a), the resonance of the terminal vinyl carbon atom of the tris(4-vinylphenyl)amine monomer at about $114 \mathrm{ppm}$ was not detected for $\mathrm{Pd} @ \mathrm{~N}=\mathrm{P}$ or $\mathrm{Pd} @ \mathrm{~N}=\mathrm{P}=\mathrm{O}$. The peak at approximately $148.0 \mathrm{ppm}$ was attributed to the quaternary $\mathrm{N}-\mathrm{C}_{\mathrm{ar}}$ sites for both porous polymers. ${ }^{40}$ Two signals at approximately $130.0 \mathrm{ppm}$ and $147 \mathrm{ppm}$ for the two polymers corresponded to the carbon atoms of the ethylene $C_{\mathrm{ar}}-\mathrm{CH}=\mathrm{CH}-C_{\mathrm{ar}}$ units and the $\mathrm{C}_{\mathrm{ar}}-\mathrm{P}$ sites, respectively. ${ }^{41} \mathrm{In}$ the solid-state ${ }^{31} \mathrm{P}$ CP/MAS NMR spectra (Fig. 1b), for $\mathrm{Pd} @ \mathrm{~N}=\mathrm{P}=\mathrm{O}$, a signal at $28.5 \mathrm{ppm}$ arose from the $-\mathrm{P}=\mathrm{O}$ moiety. While, in the case of $\mathrm{Pd} @ \mathrm{~N}=\mathrm{P}$, two signals at about $25.3 \mathrm{ppm}$ and $-7.0 \mathrm{ppm}$ were observed, corresponding to quaternary phosphonium and tertiary phosphine atoms, respectively. ${ }^{42,43}$ These results indicate that a high degree of polymerization has been achieved by using the Pd-catalyzed Heck cross-coupling reaction.

For comparison, the Fourier transform infrared (FTIR) spectra of tris(4-vinylphenyl)amine, $\quad \mathrm{Pd} @ \mathrm{~N}=\mathrm{P} \quad$ and $\mathrm{Pd} @ \mathrm{~N}=\mathrm{P}=\mathrm{O}$ were collected and are shown in Fig. 2a. The characteristic mono-substituted terminal $\mathrm{C}=\mathrm{C}$ vibration peak appears at about $910 \mathrm{~cm}^{-1}$ for the tris(4-vinylphenyl)amine. ${ }^{9}$ While for $\mathrm{Pd} @ \mathrm{~N}=\mathrm{P}$ and $\mathrm{Pd} @ \mathrm{~N}=\mathrm{P}=\mathrm{O}$, the peak at about $910 \mathrm{~cm}^{-1}$ disappeared, and a low-intensity peak at around $962 \mathrm{~cm}^{-1}$ was observed, which is the characteristic vibration peak of the bis-substituted $\mathrm{C}=\mathrm{C}$, indicating the complete consumption of the tris(4-vinylphenyl)amine monomer after the Heck cross-coupling reaction. The structures and thermal stabilities of the polymers were examined using X-ray diffraction (XRD) and thermogravimetric analysis, respectively. The $\mathrm{XRD}$ of $\mathrm{Pd} @ \mathrm{~N}=\mathrm{P}$ and $\mathrm{Pd} @ \mathrm{~N}=\mathrm{P}=\mathrm{O}$ indicates amorphous morphologies, which are typical for porous polymers formed through metal-catalyzed coupling reactions (Fig. 2b). Thermogravimetric analysis (TGA) (Fig. 2c) under a nitrogen atmosphere disclosed that both $\mathrm{Pd} @ \mathrm{~N}=\mathrm{P}$ and $\mathrm{Pd} @ \mathrm{~N}=\mathrm{P}=\mathrm{O}$ exhibit a high thermal stability with only a $5 \%$ weight loss at 400 and $550{ }^{\circ} \mathrm{C}$, respectively, which is the same as the previously reported P-containing porous polymers. ${ }^{37}$ The good thermal stabilities for these types of porous polymers could be reasonably assigned to their conjugated aromatic frameworks. The

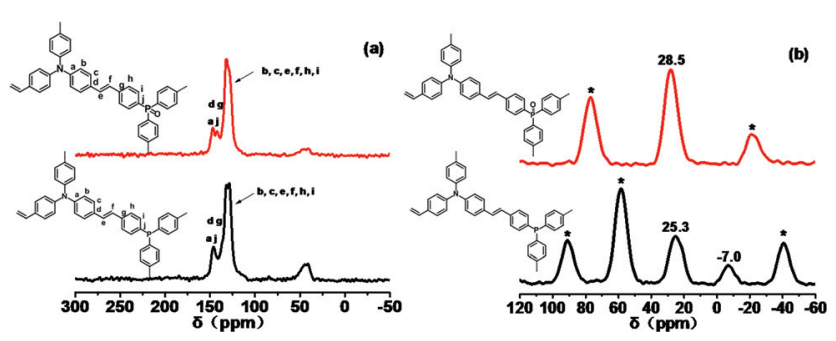

Fig. 1 (a) ${ }^{13} \mathrm{C} C P-M A S N M R$ spectra of the $P d a N=P$ and $P d a N=P=O$. (b) ${ }^{31} \mathrm{P}$ CP-MAS NMR spectra of the $\mathrm{Pd} @ \mathrm{~N}=\mathrm{P}$ and $\mathrm{Pd} \mathrm{aN}=\mathrm{P}=\mathrm{O}$ (* attributed to side bands ${ }^{43}$ ). 

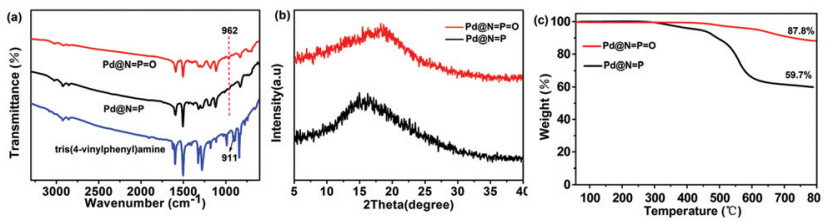

Fig. 2 Characterization of $\mathrm{Pd} a \mathrm{~N}=\mathrm{P}$ and $\mathrm{Pd} a \mathrm{~N}=\mathrm{P}=\mathrm{O}$ : (a) FTIR spectra compared with tris(4-vinylphenyl)amine; (b) XRD patterns and (c) TGA curves.

elemental components of the $\mathrm{Pd} @ \mathrm{~N}=\mathrm{P}$ and $\mathrm{Pd} @ \mathrm{~N}=\mathrm{P}=\mathrm{O}$ samples were further examined by mapping. Of note, the elemental mapping images show uniform distributions of carbon, phosphorus, and palladium elements in the network of $\mathrm{Pd} @ \mathrm{~N}=\mathrm{P}$ (Fig. 3 and $\mathrm{S} 2 \dagger$ ) and $\mathrm{Pd@N=P=O}$ (Fig. $\mathrm{S} 3$ and $\mathrm{S} 4 \dagger$ ).

The porous structures of $\mathrm{Pd} @ \mathrm{~N}=\mathrm{P}$ and $\mathrm{Pd} @ \mathrm{~N}=\mathrm{P}=\mathrm{O}$ were measured by nitrogen adsorption-desorption isotherm measurements at $77 \mathrm{~K}$ (Fig. 4a). The nitrogen adsorption and desorption isotherms revealed that both porous polymers exhibit type II isotherms according to the IUPAC classification. $\mathrm{Pd} @ \mathrm{~N}=\mathrm{P}$ possesses a much lower surface area (BrunauerEmmett-Teller (BET) value: $381 \mathrm{~m}^{2} \mathrm{~g}^{-1}$; Langmuir surface area: $\left.481 \mathrm{~m}^{2} \mathrm{~g}^{-1}\right)$ and a smaller total pore volume $\left(0.239 \mathrm{~cm}^{3}\right.$ $\mathrm{g}^{-1}$ ) than $\mathrm{Pd} @ \mathrm{~N}=\mathrm{P}=\mathrm{O}$ (BET value: $684 \mathrm{~m}^{2} \mathrm{~g}^{-1}$; Langmuir
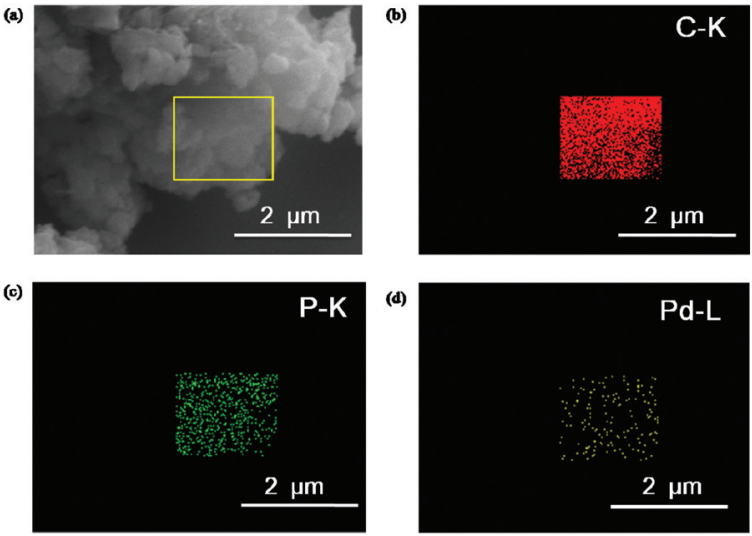

Fig. 3 (a) Typical scanning electron microscopy (SEM) image of $\mathrm{Pd} @ \mathrm{~N}=\mathrm{P}$ and the corresponding elemental mapping images of (b) carbon, (c) phosphorus, and (d) palladium in the selected area.
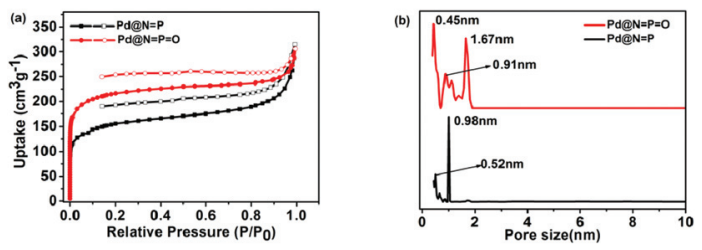

Fig. 4 (a) Nitrogen adsorption-desorption analysis of the porous polymers; (b) pore size distribution of the porous polymers. surface area: $702 \mathrm{~m}^{2} \mathrm{~g}^{-1}$; total pore volume: $0.342 \mathrm{~cm}^{3} \mathrm{~g}^{-1}$ ). The pore size distributions of $\mathrm{Pd} @ \mathrm{~N}=\mathrm{P}$ and $\mathrm{Pd} @ \mathrm{~N}=\mathrm{P}=\mathrm{O}$ were calculated using nonlocal density functional theory (NLDFT). As shown in Fig. 4b, the pore size distribution of $\mathrm{Pd} @ \mathrm{~N}=\mathrm{P}$ mainly appears at $0.98 \mathrm{~nm}$ and, approximately, at $0.52 \mathrm{~nm}$. Besides the peak at $\sim 0.91 \mathrm{~nm}$, remarkably intensive peaks were also recorded at $0.45 \mathrm{~nm}$ and $1.67 \mathrm{~nm}$ for $\mathrm{Pd} @ \mathrm{~N}=\mathrm{P}=\mathrm{O}$. These compare with most of the reported CMPs, COFs, and MOFs which have small pores of less than $2 \mathrm{~nm}$. The phosphorus(III) linker, bearing one lone pair of electrons, projects toward the trigonal pyramid structure, and thus likely endows the network of $\mathrm{Pd} @ \mathrm{~N}=\mathrm{P}$ with less rigidity. Meanwhile, the phosphorus(v) atom of the phosphoryl group in the network of $\mathrm{Pd} @ \mathrm{~N}=\mathrm{P}=\mathrm{O}$ adopts a tetrahedral geometrical structure with an increased rigidity, which would be favorable for the formation of a much more spacious scaffold. ${ }^{31,39}$ On the other hand, in comparison with the building block tris(4-bromophenyl)phosphine, tris(4-bromophenyl)phosphine oxide, with a stronger electron-withdrawing phosphoryl group, offers an enhanced polarity. ${ }^{44}$ These structural and electronic characteristics of the building blocks might benefit an increased degree of polymerization for $\mathrm{Pd} @ \mathrm{~N}=\mathrm{P}=\mathrm{O}$. Hence, a much better thermal stability and a pronounced increase in the surface area and pore size were achieved for $\mathrm{Pd} @ \mathrm{~N}=\mathrm{P}=\mathrm{O}$ in comparison to those of $\mathrm{Pd} @ \mathrm{~N}=\mathrm{P}$. Moreover, the morphologies and microstructures of $\mathrm{Pd} @ \mathrm{~N}=\mathrm{P}$ and $\mathrm{Pd} @ \mathrm{~N}=\mathrm{P}=\mathrm{O}$ were investigated by transmission electron microscopy (TEM) (Fig. 5). The alternating areas of light and dark contrast in the TEM images revealed their disordered porous structural natures.

In order to gain insight into the structural information, in particular the state of the palladium element in the networks of these polymers, X-ray photoelectron spectroscopy (XPS) measurements were performed. They revealed two broad peaks at $336.8 \mathrm{eV}$ and $342.1 \mathrm{eV}$, as displayed in Fig. S4, $\dagger$ suggesting the existence of both $\operatorname{Pd}(0)$ and $\operatorname{Pd}(\mathrm{II})$ in $\mathrm{Pd} @ N=\mathrm{P}$ and $\mathrm{Pd} @ \mathrm{~N}=\mathrm{P}=\mathrm{O} .{ }^{45}$ On the basis of XPS analysis, the content of the Pd element in both of porous polymers can be evaluated as $1.10 \mathrm{wt} \%$ and $0.97 \mathrm{wt} \%$ for $\mathrm{Pd} @ \mathrm{~N}=\mathrm{P}$ and $\mathrm{Pd} @ \mathrm{~N}=\mathrm{P}=\mathrm{O}$, respectively, which are consistent with those values from the aforementioned ICP analysis.

Pd-based catalysts have been extensively used in homogeneous systems for the formation of carbon-carbon or carbon-heteroatom bonds. ${ }^{46,47}$ Owing to Pd being a high-cost,
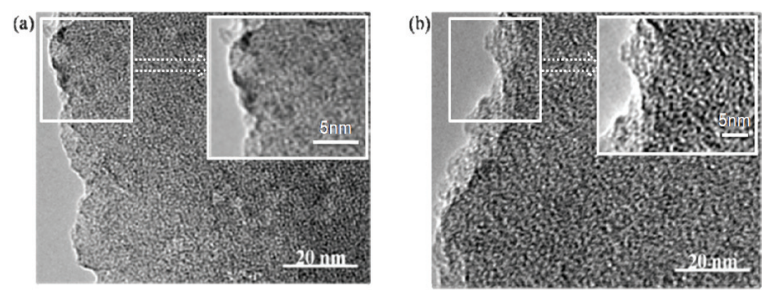

Fig. 5 TEM images of (a) $\mathrm{Pd}(\mathrm{N}=\mathrm{P}$ and (b) $\mathrm{Pd}(\mathrm{N}=\mathrm{P}=\mathrm{O}$. 
scarce resource, the development of reusable and recyclable Pd catalysts, for example, for heterogeneous Pd-based catalysis, is desirable when taking environmental, economic and safety factors into account. In this respect, $\mathrm{Pd} @ \mathrm{~N}=\mathrm{P}$ and $\mathrm{Pd} @ \mathrm{~N}=\mathrm{P}=\mathrm{O}$ were examined as catalysts for the SuzukiMiyaura coupling reaction. All reactions were directly performed under aerobic conditions (in water/EtOH, with a base of $\mathrm{K}_{2} \mathrm{CO}_{3}$ at $70{ }^{\circ} \mathrm{C}$, without the addition of extra ligands and degassing treatment of the reaction system, and exposed to air). As an example, with only $0.1 \mathrm{~mol} \%$ of the $\mathrm{Pd} @ \mathrm{~N}=\mathrm{P}$ catalyst (the content is calculated relative to the aryl bromides), the coupling reaction of phenylboronic acid with substituted aryl bromides can smoothly occur in air, affording coupling products in a nearly quantitative yield within a very short time after a simple workup procedure (entries 1-3 in Table 1) (for the experimental details, see the Experimental section). It only took 1.5 hours for most of the reactions to achieve the coupling products in good yields, making such kinds of Pd-loaded porous polymers among the most effective catalysts for Suzuki cross-couplings. ${ }^{30}$ The superior catalytic performance of $\mathrm{Pd} @ \mathrm{~N}=\mathrm{P}$ is presumably due to the triarylphosphine units in the microporous structure, which might provide effective binding sites for Pd atoms, and the adsorption of the reactants into the porous channels by capillary condensation of the micropores, which is where the catalytic sites are located. As a comparison, $\mathrm{Pd}\left(\mathrm{PPh}_{3}\right)_{4}(1.3 \mathrm{mg}$, equal to the amount of the $\mathrm{Pd}$ in $10 \mathrm{mg}$ of the $\mathrm{Pd} @ \mathrm{~N}=\mathrm{P}$ above) was seen to catalyze the reaction of phenyl bromide and phenylboronic acid under the same reaction conditions without the addition of extra ligands, affording the cross-coupling product in a yield of only $55.4 \%$. This result might be attributed to the deactivation of the traditional catalyst $\left[\mathrm{Pd}\left(\mathrm{PPh}_{3}\right)_{4}\right]$, as a reduced amount of the

Table 1 Suzuki-Miyaura coupling reactions using $\mathrm{Pd} a \mathrm{~N}=\mathrm{P}$ and $\mathrm{Pd} \mathrm{aN}=\mathrm{P}=\mathrm{O}^{a}$

\begin{tabular}{llll}
\hline & & & \\
\hline & & & \\
\hline
\end{tabular}

${ }^{a}$ Reaction conditions: $1 \mathrm{mmol}$ aryl bromide, $1.5 \mathrm{mmol}$ arylboronic acid, $2 \mathrm{mmol} \mathrm{K}_{2} \mathrm{CO}_{3}, 10 \mathrm{mg}$ catalyst, and $\mathrm{H}_{2} \mathrm{O} / \mathrm{EtOH}(1: 3 \mathrm{v} / \mathrm{v})$ at $70{ }^{\circ} \mathrm{C}$ for $1-2 \mathrm{~h}$. assistant ligand was used, which seems to be avoided in the heterogeneous catalytic system of the as-prepared Pd-loaded porous polymer. Such a phenomenon was also observed in the other phosphorus-containing porous polymers for catalyzing hydroformylations, which were just reported during the preparation of our manuscript. ${ }^{48}$ On the other hand, the catalytic properties of the as-prepared porous polymers highly depend on the porous structures, which were elucidated by their catalytic behaviors after using varying substrates. Taking $\mathrm{Pd} @ \mathrm{~N}=\mathrm{P}$ as the catalyst under similar reaction conditions as those aforementioned, the different substrates $p$-methyl-bromobenzene, $p$-ethyl-bromobenzene and $p$-propyl-bromophenyl were reacted with phenylboronic acid, affording the coupling products p-methylbiphenyl, $p$-ethylbiphenyl and $p$-propylbiphenyl in yields of $80.4 \%, 55.2 \%$ and $18.9 \%$, respectively (entries 6-8, Table 1). Obviously, increasing the size of the substituent group in the $p$-position of the substrate directly led to a decline in the yield of the corresponding cross-coupling product as a consequence of the steric effect of the porous structure of $\mathrm{Pd} @ \mathrm{~N}=\mathrm{P}$. Further, using a phenyl derivative with the substituent group at the $m$ - or $o$-position as the substrate also resulted in remarkably different yields (entries 4 and 5 , Table 1), verifying the spacial effect of the porous network of the as-prepared polymers on the catalytic behaviors. $\mathrm{Pd} @ \mathrm{~N}=\mathrm{P}=\mathrm{O}$, with a larger average pore size than $\mathrm{Pd} @ \mathrm{~N}=\mathrm{P}$, exhibits higher catalytic activities, indicating the space-confinement effect of the porous structure on the reactants. Additionally, the coupling of phenylboronic acid with chlorobenzene only gave a $35.5 \%$ yield (entry 14 , Table 1 ), probably due to the sluggish activity of the aryl chloride with respect to that of the aryl bromide under the experimental conditions, which might be improved by optimizing the reaction conditions or performance under an inert atmosphere. In the case of using 4-methoxy-bromobenzene and phenylboronic acid as substrates, the yield of the coupling product is still very high (98\%, entry 9, Table 1). However, the coupling reaction between $p$-bromobenzaldehyde and phenylboronic acid only gave the coupling product with a poor yield of $11 \%$. The reason can probably be attributed to the deactivation of the $\mathrm{Pd}$ atoms by the strong polar substrates in the polymer matrix.

The recyclability and reusability of these porous polymers were examined by using phenyl bromide and phenylboronic acid as substrates. The results demonstrated that the yields of the cross-coupling products remained at more than $98 \%$ after three continuous runs, and the catalyst could be readily recovered by a simple treatment after each cycle and directly reused in the next run, indicating that such kinds of Pd-loaded porous polymers represent efficient and economic catalytic systems.

To consider if the amount of $\operatorname{Pd}\left(\mathrm{PPh}_{3}\right)_{4}$ used in the polymerization would have a significant effect on the content of the Pd element in the networks and the porosities of the resulting porous polymers, we also examined the polymerization of tris(4-vinylphenyl)amine with tris(4-bromophenyl)phosphine under $1 \% \mathrm{mmol}$ and $8 \% \mathrm{mmol}$ of the $\mathrm{Pd}\left(\mathrm{PPh}_{3}\right)_{4}$ catalyst, comparing with that of $4 \% \mathrm{mmol}$ of $\mathrm{Pd}\left(\mathrm{PPh}_{3}\right)_{4}$. The 
loading amount of Pd in the resulting polymer samples, confirmed by the inductively coupled plasma (ICP) analysis, was $0.64 \mathrm{wt} \%, 1.0 \mathrm{wt} \%$ and $4.67 \mathrm{wt} \%$ with respect to the usage of $1 \% \mathrm{mmol}, 4 \% \mathrm{mmol}$ and $8 \% \mathrm{mmol}$ of the $\mathrm{Pd}\left(\mathrm{PPh}_{3}\right)_{4}$ catalyst for the polymerization. The yields of the porous polymers are also increased when a greater amount of the Pd catalyst was used, which was likely due to the enhancement of the degree of the polymerization. Accordingly, the porous structures of the resulting porous polymers also varied, and the polymer product with the largest surface area was found in the case of $4 \% \mathrm{mmol}$ of $\mathrm{Pd}\left(\mathrm{PPh}_{3}\right)_{4}$. These results indicate that the amount of the $\mathrm{Pd}\left(\mathrm{PPh}_{3}\right)_{4}$ catalyst used for the polymerization has a significant effect on the characters of the resulting polymers, including the content of Pd element loaded into the networks (Fig. S5 and Table S1†).

\section{Conclusions}

In summary, the Pd-loaded microporous polymers $\mathrm{Pd} @ \mathrm{~N}=\mathrm{P}$ and $\mathrm{Pd} @ \mathrm{~N}=\mathrm{P}=\mathrm{O}$, with $\mathrm{P}$ (III) atoms bearing one lone pair of electrons and the $\mathrm{P}(\mathrm{v})$ atoms of the phorsphoryl groups as linkers in the networks, respectively, were effectively synthesized by one-pot Pd-catalyzed Heck coupling reactions. The Pd-catalyst used for the in situ polymerization of the two porous polymers serves as the source of Pd atom which is uniformly embedded in the network of these polymers. $\mathrm{Pd} @ \mathrm{~N}=\mathrm{P}=\mathrm{O}$ exhibits a much higher thermal stability, larger surface area and pore size than $\mathrm{Pd} @ \mathrm{~N}=\mathrm{P}$. These polymers enable the effective catalysis of the Suzuki cross-coupling reaction under aerobic conditions. The activities of the as-prepared porous polymers exhibit pronounced size-selection properties, confined by the spacial effects of the porous structures of the networks. They showed excellent catalyst recyclability and reusability. The catalytic activity of $\mathrm{Pd} @ \mathrm{~N}=\mathrm{P}=\mathrm{O}$ is much higher than that of $\mathrm{Pd} @ \mathrm{~N}=\mathrm{P}$. The phosphorus linkers with different valence states in the networks play a crucial role in the different structures and properties of the two porous polymers, which will be explored for building new material systems applicable for transforming organic substrates to much more complex structures with a wide scope.

\section{Acknowledgements}

This work was financially supported by the National Basic Research Program of China (973 Program: 2013CBA01602, 2012CB933404), the Natural Science Foundation of China (21174083, 51403126 and 21102091), and the Shanghai Committee of Science and Technology (15JC1490500).

\section{Notes and references}

1 F. S. Han, Chem. Soc. Rev., 2013, 42, 5270.

2 Y. Xiong, B. J. Wiley and Y. Xia, Angew. Chem., Int. Ed., 2007, 46, 7157.
3 M. Lamblin, L. Nassar-Hardy, J. C. Hierso, E. Fouquet and F.-X. Felpin, Adv. Synth. Catal., 2010, 352, 33.

4 R. B. Bedford, U. G. Singh, R. I. Walton, R. T. Williams and S. A. Davis, Chem. Mater., 2005, 17, 701.

5 B. M. Choudary, S. Madhi, N. S. Chowdari, M. L. Kantam and B. Sreedhar, J. Am. Chem. Soc., 2002, 124, 14127.

6 Y. Kitamura, S. Sako, T. Udzu, A. Tsutsui, T. Maegawa, Y. Monguchi and H. Sajiki, Chem. Commun., 2007, 5069, DOI: 10.1039/B712207A.

7 S. Y. Ding, J. Gao, Q. Wang, Y. Zhang, W. G. Song, C. Y. Su and W. Wang, J. Am. Chem. Soc., 2011, 133, 19816.

8 P. Kaur, J. T. Hupp and S. T. Nguyen, ACS Catal., 2011, 1, 819.

9 L. Sun, Z. Liang, J. Yu and R. Xu, Polym. Chem., 2013, 4, 1932.

10 L. Sun, Y. Zou, Z. Liang, J. Yu and R. Xu, Polym. Chem., 2014, 5, 471.

11 R. Dawson, E. Stockel, J. R. Holst, D. J. Adams and A. I. Cooper, Energy Environ. Sci., 2011, 4, 4239.

12 W. C. Song, X. K. Xu, Q. Chen, Z. Z. Zhuang and X. H. Bu, Polym. Chem., 2013, 4, 4690.

13 Y. Zhang and S. N. Riduan, Chem. Soc. Rev., 2012, 41, 2083.

14 F. Vilela, K. Zhang and M. Antonietti, Energy Environ. Sci., 2012, 5, 7819.

15 Y. Xu, S. Jin, H. Xu, A. Nagai and D. Jiang, Chem. Soc. Rev., 2013, 42, 8012.

16 S. Ren, R. Dawson, A. Laybourn, J. X. Jiang, Y. Khimyak, D. J. Adams and A. I. Cooper, Polym. Chem., 2012, 3, 928.

17 L. J. Abbott and C. M. Colina, Macromolecules, 2014, 47, 5409.

18 M. Seo, S. Kim, J. Oh, S. J. Kim and M. A. Hillmyer, J. Am. Chem. Soc., 2015, 137, 600.

19 S. Y. Ding and W. Wang, Chem. Soc. Rev., 2013, 42, 548.

20 X. Feng, X. Ding and D. Jiang, Chem. Soc. Rev., 2012, 41, 6010.

21 B. S. Ghanem, Polym. Chem., 2012, 3, 96.

22 J. Vile, M. Carta, C. G. Bezzu and N. B. McKeown, Polym. Chem., 2011, 2, 2257.

23 P. Arab, A. Verlander and H. M. El-Kaderi, J. Phys. Chem. C, 2015, 119, 8174.

24 A. M. Shultz, O. K. Farha, J. T. Hupp and S. T. Nguyen, Chem. Sci., 2011, 2, 686.

25 X. Liu, H. Li, Y. Zhang, B. Xu, S. A. H. Xia and Y. Mu, Polym. Chem., 2013, 4, 2445.

26 A. Modak, M. Pramanik, S. Inagaki and A. Bhaumik, J. Mater. Chem. A, 2014, 2, 11642.

27 A. Bhunia, V. Vasylyeva and C. Janiak, Chem. Commun., 2013, 49, 3961.

28 S. Kidambi and M. L. Bruening, Chem. Mater., 2004, 17, 301.

29 F. Wang, J. Mielby, F. H. Richter, G. Wang, G. Prieto,

T. Kasama, C. Weidenthaler, H. J. Bongard, S. Kegnaes,

A. Furstner and F. Schuth, Angew. Chem., Int. Ed., 2014, 53, 8645.

30 Q. Song, Y. Jia, B. Luo, H. He and L. Zhi, Small, 2013, 9, 2460.

31 C. Liu, Y. Li, Y. Li, C. Yang, H. Wu, J. Qin and Y. Cao, Chem. Mater., 2013, 25, 3320. 
32 S. O. Jeon and J. Y. Lee, J. Mater. Chem., 2012, 22, 4233.

33 T. Li, S. Kaercher and P. W. Roesky, Chem. Soc. Rev., 2014, 43, 42.

34 P. J. C. Hausoul, T. M. Eggenhuisen, D. Nand, M. Baldus, B. M. Weckhuysen, R. J. M. Klein Gebbink and P. C. A. Bruijnincx, Catal. Sci. Technol., 2013, 3, 2571.

35 S. Qiao, W. Huang, Z. Du, X. Chen, F. K. Shieh and R. Yang, New J. Chem., 2015, 39, 136.

36 Y. Tao, C. Yang and J. Qin, Chem. Soc. Rev., 2011, 40, 2943.

37 Q. Zhang, Y. Yang and S. Zhang, Chem. - Eur. J., 2013, 19, 10024.

38 P. Taranekar, Q. Qiao, H. Jiang, I. Ghiviriga, K. S. Schanze and J. R. Reynolds, J. Am. Chem. Soc., 2007, 129, 8958.

39 Y. Wang, M. I. Ranasinghe and T. Goodson, J. Am. Chem. Soc., 2003, 125, 9562.

40 J. X. Jiang, A. Trewin, F. Su, C. D. Wood, H. Niu, J. T. A. Jones, Y. Z. Khimyak and A. I. Cooper, Macromolecules, 2009, 42, 2658.
41 Q. Zhang, S. Zhang and S. Li, Macromolecules, 2012, 45, 2981.

42 S. L. Qiao, W. Huang, Z. K. Du, X. H. Chen, F. K. Shiehc and R. Q. Yang, New J. Chem., 2015, 39, 136.

43 P. J. C. Hausoul, T. M. Eggenhuisen, D. Nand, M. Baldus, B. M. Weckhuysen, R. J. M. K. Gebbink and P. C. A. Bruijnincx, Catal. Sci. Technol., 2013, 3, 2571.

44 X. Chen, S. Qiao, Z. Du, Y. Zhou and R. Yang, Macromol. Rapid Commun., 2013, 34, 1181.

45 Y. Dai, S. Liu and N. Zheng, J. Am. Chem. Soc., 2014, 136, 5583.

46 H. Li, C. C. C. Johansson Seechurn and T. J. Colacot, ACS Catal., 2012, 2, 1147.

47 N. Kambe, T. Iwasaki and J. Terao, Chem. Soc. Rev., 2011, 40, 4937.

48 Q. Sun, Z. Dai, X. Liu, N. Sheng, F. Deng, X. Meng and F. S. Xiao, J. Am. Chem. Soc., 2015, 137, 5204. 